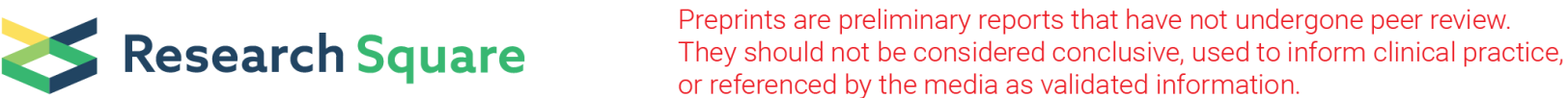

\section{Landscape Simplification Increases Bactrocera Oleae Abundance In Olive Groves: Populations Dynamics In Different Land Uses.}

Daniel Paredes ( $\nabla$ daniel.paredes@uc.pt)

University of Coimbra https://orcid.org/0000-0002-2681-2256

João Frederico Alves

University of Coimbra

\section{Sara Mendes}

University of Coimbra https://orcid.org/0000-0002-5447-0038

José Miguel Costa

University of Coimbra https://orcid.org/0000-0002-4991-7122

Joana Alves

University of Coimbra https://orcid.org/0000-0003-2858-7803

António Alves da Silva

University of Coimbra https://orcid.org/0000-0001-9544-3936

José Paulo Sousa

University of Coimbra https://orcid.org/0000-0001-8045-4296

\section{Research Article}

Keywords: pest management, land uses, landscape diversification, olive fly

Posted Date: November 30th, 2021

DOI: https://doi.org/10.21203/rs.3.rs-1068293/v1

License: (9) This work is licensed under a Creative Commons Attribution 4.0 International License.

Read Full License

Version of Record: A version of this preprint was published at Journal of Pest Science on March 28th, 2022. See the published version at https://doi.org/10.1007/s10340-022-01489-1. 


\section{Abstract}

Bactrocera oleae is the main pest in olive groves and its management requires a sustainable perspective to reduce the use of chemical products. Landscape context is being considered as an important driver of pest reduction but results on $B$. oleae show inconsistency to date. Most of landscape-pest control studies focus on the dynamics of the pests within the focal crop, ignoring these dynamics in other land uses. Here we present a study in which we analyze the seasonal population dynamics of the olive pest $B$. oleae in the most important land uses of a typical olive landscape in Portugal. We found that $B$. oleae is present in all the land uses and the dynamics are very similar to those in the olive groves. However, the presence of these land uses in the landscape did not display any increase of B.oleae abundance within the olives groves. In contrast, a landscape mainly composed by olive groves increased the abundance of this pest. Importantly, more diverse landscapes surrounding olive groves reduce the abundance of the olive fly. Based on these findings, we can conclude that $B$. oleae is present in all the land uses of the studied landscape but that this presence does not imply an increase of $B$. oleae in olive groves. Indeed, other land uses can promote landscape diversification which is a driver of the reduction of $B$. oleae populations in olive groves. We thus encourage olive stakeholders to increase landscape diversification around their farms by promoting/restoring other crops/habitats.

\section{Introduction}

In the last decades, agriculture has passed through an intensification process by drastically increasing the land devoted to farming for food production (Foley et al. 2005). This process has resulted in the loss of natural habitats which in turn has provoked a loss of biodiversity and a reduction of the ecosystem services associated with it (Dirzo et al. 2014). In addition, this landscape simplification process increases the likelihood of more damaging and catastrophic pest outbreaks (Paredes et al. 2021), which has intensified farmers' dependence on insecticides. However, the resistance of pests to insecticides is augmenting, even exceeding the capacity to generate new products to combat these pests (Gould et al. 2018). Because of this, new policies are promoting the use of sustainable solutions for pest management that do not imply the use of this kind of products (European Comission 2020). Despite most of the techniques that have been tested are orientated towards its implementation at the local level, ecologists, agronomists and farmers are increasingly recognizing the critical role that surrounding landscapes can play in determining pest damage (Thies and Tscharntke 1999; Bianchi et al. 2006).

Simplified landscapes (i.e., expansive monocultures) can increase pest outbreaks because they promote specialized pest populations to develop and spread more easily, whereas complex landscapes (i.e., mosaics of different land uses) can be a barrier that hamper this expansion (Root 1973; O'Rourke and Petersen 2017). On the other hand, diversified landscapes can promote pest natural enemies (predators and parasitoids) by providing resources such as shelter, nectar, pollen and/or alternative prey for their optimal development, thus improving their action against pests (Landis et al. 2000; Chaplin-Kramer et al. 2011). Therefore, planting multiple crops or retaining non-crop vegetation may lower pest densities and reduce insecticide applications (Dainese et al. 2019; Paredes et al. 2021). However, pests can also use 
other land uses in the landscape for their development thus increasing their presence into the crop (Tscharntke et al. 2016). For example, in Africa, corn stemborers appeared to be promoted by grasslands (Midega et al. 2014), which aligns with another study in Australia that also showed natural grasslands as a source of pest (Parry et al. 2015). Perhaps, the most critical case is the invasive pest species Drosophila suzukii that seems to be positively affected by natural habitats at the landscape scale, by using alternative hosts to thrive (Santoiemma et al. 2018) and also because these habitats provide better protection against adverse weather conditions during winter and summer periods (Santoiemma et al. 2019). Thus, the inconsistency of pest responses to landscape complexity prevents researchers to emit clear conclusions about the role of landscape on pest control (Karp et al. 2018). It also highlighting the importance of pest species' traits to elucidate its responses to landscape composition (Tamburini et al. 2020) as well as on how they interact with the different elements in the landscape.

Bactrocera oleae (Rossi) is the major olive pest that induces economic losses worldwide totaling approximately $15 \%$ per year (Montiel-Bueno and Jones 2001). The effect of landscape context on this pest is not well defined. For example, a study performed in southern Spain showed a reduction of this pest in areas with more natural habitat edge density, landscape diversity and higher number of patches of natural vegetation (Ortega and Pascual 2014). However, another study carried out in Italy did not find any effect of natural habitats on B. oleae abundance (Picchi et al. 2016), whereas another work developed in southern Spain showed a positive effect of natural habitats on B. oleae abundance (Manjón-Cabeza et al. 2017). The stochasticity that pest populations have may be behind these contrasting results (ChaplinKramer et al. 2013; Paredes et al. 2021). However, neither of these studies nor most of the others regarding the effect of landscape on other pests (but see Santoiemma et al. 2019) have ever explored whether the population dynamics of this pest in other land uses is different or similar from that in the olive grove.

Even more, the olive fly has a period during the year in which it disappears from the olive groves. This is called the "white period" that takes place in the months of May and June when the abundance of olive fly in the field suddenly drops and there are no olive fruits to attack (Michelakis and Neuenschwander 1981). During this period, the olive fly can move in the landscape looking for other resources that ultimately can reinforce its population when this start rising in Autumn (Marchini et al. 2017). Therefore, to understand the population dynamics of $B$. oleae in other land uses is critical to understand the importance of a landscape perspective in the management of this pest and how can we better promote natural pest control mechanisms based on landscape management (Daane and Johnson 2010).

Here we purpose a study in which we investigate the dynamics of $B$. oleae in the different land uses that compound a typical olive landscape in Portugal. We aim at answering the following questions: (1) To what extent is Bactrocera oleae present in the different land uses, including olive grove? (2) Which are the dynamics of $B$. oleae in these land uses? and, (3) How different land uses at the landscape scale affect the abundance of Bactrocera oleae in olive groves?

\section{Material And Methods}




\subsection{Study sites and insect sampling}

To achieve the objectives of this study, a total of 79 sampling points distributed among the most common land uses detected in the sampling area located in the Beira Interior region of Portugal within the municipalities of Castelo Branco and Idanha-a-Nova were selected (Figure 1). The land uses detected in this area were shrublands, eucalyptus forests, pine forests, "montado" (Iberian oaks savannahs), grasslands, vineyards and olive groves. As it is the main land use of the study and the place where the activity of $B$. oleae takes place, of the total of 79 sampling points, 25 points were located in olive groves. The twenty-five olive groves were mostly centenary of the same variety (Galega), non-irrigated and with low groundcover vegetation due to livestock presence. During this study, olive growers did not apply pesticides and did not use land ploughing methods. The rest of sampling points were distributed among the other land uses at the rate of nine for each one (Figure 1).

To determine $B$. oleae abundance, a McPhail trap were placed at each one of the points selected in February 2019 (Figure 1). Each trap was filled with a liquid content consisting of a $250 \mathrm{~mL}$ aqueous solution with $5 \%$ diammonium phosphate and $2 \%$ borax, which is very effective in attracting $B$. oleae adults (Porcel et al. 2009). Samples were monthly collected for one year starting in February 2019 and ending in January 2020. After collection in the field, samples were transported to the laboratory where individuals of $B$. oleae were counted.

\subsection{Landscape analysis}

At each of the 25 sampling points located in olive groves, a geospatial analysis of the surrounding buffer area with a radius of $500 \mathrm{~m}$ was performed using QGIS software (Open-Source Geospatial Foundation. Beaverton. OR. USA), a Geographic Information Systems (GIS) platform. Based on aerial photographs, we delineated polygons by representing the different patches of the different land uses found in the study area already mentioned above. To validate misalignment of the landscape elements, in addition to adding data to the elements that cannot be identified from the aerial photographs, it was necessary to perform a visual field validation to confirm land use of each selected point. All of this geospatial information was converted to raster images and analyzed into Fragstats software (University of Massachusetts. Amherst, MA. USA). From this spatial pattern analysis, we obtained class-level landscape metrics, in which the total area of each patch within each of the landscape buffer zones was quantified through the landscape percentage. From these values, we then obtained the Shannon's diversity index (SHDI) that we used as a proxy of landscape diversity. To estimate landscape simplification, we used the proportion of the olive land use surrounding the sampling point.

\subsection{Modeling}

To determine the presence of $B$. oleae in the different land uses present at the study area, we first added all the individuals counted at each sampling date to get a single value per sampling point. We then stablished statistically significant differences between sets of pairs of land uses by using a nonparametric Wilcoxon rank sum test with p-values adjusted by the Benjamini \& Hochberg method 
(Benjamini and Hochberg 1995). Then, for better representation in a boxplot we log-transformed the data used to perform this test.

To account for the dynamics of $B$. oleae in the different habitats during one year, we used Generalized Additive Mixed Models (GAMMs) with a predictor in the form of an interaction between the Julian day in which the traps were sampled and the land use in which they were located. Number of knots were set at five to allow for the representations of the fluctuations of the population at each land use. Finally, we added the location of the trap (sampling point) as a random factor to control for the pseudorreplication over the time as several samples were collected in the same point at different moments of the year. We first modeled this combination of factors with a Poisson error distribution for being the nature of the response variable a count but, after testing for overdispersion, we finally decided to model it with a negative binomial error distribution with a log link function to account for overdispersion. To account for model stability, we performed the population dynamic models for each one of the land uses separately and obtaining very similar result in terms of significant dynamics ( $p$-value $<0.05$ ).

To account for the effect of the different land uses on $B$. oleae abundance in olive groves, we also used the pooled dataset applied in the first analysis that contains a single value for each one of the 25 olive groves sampled. We thus decided to perform a model selection approach based on the Akaike Information Criteria corrected for small sample size (AICc) to choose the best model. Models with the lowest AICc and those with a difference of less than two AICc units from the lowest were chosen for further explanation. Thus, we created a set of Generalized Linear Models each one including as predictor the percentage of a single land use that were: olive, shrublands, "montado", grasslands, eucalyptus forest, pine forests, vineyards and Shannon diversity index. We complete this set of models with a null model to account for non-effects. Similarly to population dynamic models, we first opted for a Poisson error distribution but after testing for overdispersion we decided to model the data with a negative binomial error distribution and log link function. All analyses were performed in R using the packages "mgcv" for GAMMs (Wood 2011), "Ime4" for GLMs (Bates et al. 2015), "DHARMa" for overdispersion analysis (Hartig et al., 2018) and "ggplot2" to visualized results (Wickham 2016).

\section{Results}

A total of 10,315 B. oleae individuals were collected and counted during the whole experiment. They were present in all the land uses tested in this study (Fig. 2). As expected, the highest abundance was found in olive groves with a total of 8,290 individuals. In the land use "montado a total of 794 individuals were trapped followed by eucalyptus forests in which 634 individuals were collected. For the other land uses the total number of captured was lower, with 246 individuals in pine forest, 196 in vineyards, 114 in shrublands and only 34 in grasslands. These differences are reflected in figure 2 and align with the results obtained in the Wilcoxon test (Table 1). Olive groves appears as the land use having significant differences with all the rest of the land uses. "Montado" showed differences with grasslands, pine forest and olive groves but not with eucalyptus forests and vineyards. Similar results were obtained for eucalyptus forests. Shrublands only showed significant differences with olive groves and "montado". A 
similar situation occurred with pine forest and grasslands but these land uses also showed significant differences with eucalyptus forests. Finally, vineyards only displayed significant differences with olive groves.

Table 1

Statistical significant differences between sets of pairs of land uses by using a nonparametric Wilcoxon rank sum test with $p$-values adjusted by the Benjamini \& Hochberg method. Significant differences $(p<$ 0.05 ) highlighted in bold.

\begin{tabular}{|lllllll|}
\hline & $\begin{array}{l}\text { Eucalyptus } \\
\text { forests }\end{array}$ & Shrublands & Montado & $\begin{array}{l}\text { Olive } \\
\text { groves }\end{array}$ & Grasslands & $\begin{array}{l}\text { Pine } \\
\text { forests }\end{array}$ \\
\hline Shrublands & 0.053 & & & & & \\
\hline Montado & 0.691 & 0.029 & & & & \\
\hline $\begin{array}{l}\text { Olive } \\
\text { groves }\end{array}$ & $<0.001$ & $<0.001$ & 0.005 & & & \\
\hline Grasslands & 0.006 & 0.442 & 0.009 & $<0.001$ & & \\
\hline $\begin{array}{l}\text { Pine } \\
\text { forests }\end{array}$ & 0.027 & 0.376 & 0.029 & $<0.001$ & 0.685 & \\
\hline \begin{tabular}{l} 
Vineyards \\
\hline
\end{tabular} & 0.329 & 0.442 & 0.156 & $<0.001$ & 0.074 & 0.137 \\
\hline
\end{tabular}

Pest dynamics were significant in five of the seven land uses tested in this study (Figure 3). Specifically, B. oleae showed significant dynamics in olive groves, "montado". eucalyptus forests, grasslands and vineyards. Bactrocera oleae population in olive groves started raising in March, reaching a peak in May. Then, it slightly decreased until mid-July when started notably spiking to find the maximum abundance in mid-October for then decrease during the winter. Grasslands and vineyards showed a very similar pattern that reflected a sustained growth from March to October for then decrease during the winter. In contrast, the dynamics of B.oleae in eucalyptus forests and "montado" displayed a two-hump pattern with an intense growth from February to mid-April, then a decrease finding the bottom around July and August and then experiencing another growth that peaked in the beginning of November. These dynamics were very similar to the one in olive groves but the intensity of the first increase was higher than in olive groves, especially for eucalyptus forests (Figure 3).

Regarding the effect of the different land uses on the abundance of $B$. oleae in olive groves, the selected models displayed a positive effect surrounding olive groves and a negative effect of the Shannon diversity index on $B$. oleae abundance (Figure 4 ). The abundance of $B$. oleae increased more than two times from olives groves with other land uses surrounding them to places with a very simplified landscape $>90 \%$ of olive groves in the buffer area). In contrast, landscape diversification displayed a negative effect reducing the abundance of $B$. oleae two times from less diversified to more diversified landscapes. It is important to notice that the parallel effect that shows the trends for landscape simplification and landscape diversity is due to the high negative correlation among these two predictors. 


\section{Discussion}

This study demonstrated that $B$. oleae is present in the main land uses that comprise this typical Portuguese olive landscape. As expected, maximum abundance was found in olive groves, but also important abundances were found in eucalyptus forests and "montado". Our experimental design does not allow us to infer the reasons for the presence of $B$. oleae in the different land uses but we can hypothesize that they are not thriving on alternative hosts due to $B$. oleae characteristics as a specialist olive pest (Daane and Johnson 2010; Clarke 2018). In contrast, the fact that this fly appears in all the land uses tested may be related with its dispersal behavior, being able to fly around 400 meters per week (Fletcher and Kapatos 1981). When populations start to build, new adult flies disperse to other olive areas to develop the next generation (Kounatidis et al. 2008). During this migration, they can pass through patches of other land uses in which they rest and search for resources to survive. Consequently, it makes sense that the dynamics in other land uses has to be related with the dynamics in the olive groves as they are going to act as a source of olive flies. This effect can be seen in land uses such as vineyards and grassland, in which the dynamics follow the same trend than in olive groves with a sustained increase of the populations from spring to the end of the autumn. However, in eucalyptus forest, $B$. oleae abundance reached very high levels during the spring period, even more than in olive groves. This fact could be related with the utility of this land use as a shelter when climatic conditions are not favorable for $B$. oleae.

The variation of climatic variables such as temperature and humidity are related to changes in individual physiology, behavior and population dynamics of poikilothermic organisms such as insect pests, which are especially sensitive to temperature fluctuations (Block 1990). Extreme weather conditions, like heat or cold waves, can affect the survival of these organisms. However, these organisms can cope with these conditions by searching for places capable of buffering these circumstances (Scheffers et al. 2014). In this sense, behaviors such as habitat selection, dispersion or thermoregulatory movements can be crucial for individuals to deal with a thermally changing environment (Deutsch et al. 2008). This can be the case for $B$. oleae which is highly affected by high temperatures in the adult stage (Gutierrez et al. 2009). Olive cultivation is developed in areas with Mediterranean climate which is characterized for having dry and hot summers. In this sense, many studies show a $B$. oleae population decline in olive groves during this period (Gutierrez et al. 2009; Wang et al. 2009; Abd El-Salam et al. 2019), which was corroborated by our study. However, eucalyptus forests could provide shelter to these unsuitable conditions in the beginning of the spring but not during the summer, when weather conditions are more unfavorable. Even more, during the "white period", no habitat showed an increase of fly abundance compared to olive groves which makes us speculate that the decline of the populations during that period is natural and that the pest does not seek refuge in any other habitat to handle hot periods.

Critically, the fact that eucalyptus forests do not act as a reservoir to boost Bactrocera oleae populations is corroborated with the null effect that this habitat had on fly abundance within the olive grove. In this sense, landscape simplification (large areas just covered with olive groves in the landscape) and landscape diversification (diversity of land uses in the landscape) displayed the most notable effects. On the one hand, simplified landscapes allow B. oleae to easily grow as they have plenty of resources to build 
their population and spread easily because they have no barriers to impede its dispersion (Root 1973; O'Rourke and Petersen 2017). Importantly, the presence of B.oleae individuals in other land uses, as demonstrated in this study, supports the idea that these landscape elements could act as a barrier for the dispersion of this pest, which reflects its low abundance in diversified landscapes. Moreover, simplified landscapes lack natural enemies that can exert a proper top-down control of the pest population whereas diversified landscapes can provide with resources to these natural enemies allowing the delivery of natural pest control services (Chaplin-Kramer et al. 2011; Rusch et al. 2016). Thus, the implication of increasing landscape diversity seems obvious for this pest and align with other studies that detected landscape diversification as a major driver of B. oleae abundance reduction (Ortega and Pascual 2014).

\subsection{Management implications}

As a consequence of these findings, we encourage farmers, technician and politicians to promote landscape diversification in olive grove landscapes. At the individual level, farmers could better control $B$. oleae populations by planting native vegetation around their farms. However, the increase in land use diversity will depend on the coordination between groups of neighboring farmers to redesign the arrangement of the different elements of the landscape, taking advantage of the synergies provided by the orography and changing land uses in areas where the composition is not balanced. A good way to promote coordination between different agricultural stakeholders is the financial compensation programs that governments can put in place to help increase the diversity of the landscape (Batáry et al. 2015). This type of coordination based on the information we obtain from the landscape is an important and necessary step for obtaining collateral benefits related to the promotion of ecosystem services such as biodiversity conservation and human health.

\section{Declarations}

All authors declare that they have no conflict of interest. The authors have no relevant financial or nonfinancial interests to disclose. The authors have no competing interests to declare that are relevant to the content of this article. All authors certify that they have no affiliations with or involvement in any organization or entity with any financial interest or non-financial interest in the subject matter or materials discussed in this manuscript. The authors have no financial or proprietary interests in any material discussed in this article.

\section{Acknowledgements}

The authors are grateful to the Association of Olive Oil Producers of Beira Interior (APABI, Portugal) for all the effort and care in identifying and detecting the landowners we required, as well as to all the olive growers who kindly allowed the traps to remain on their properties during the trial period. We thank M. Sc. Danielle Rudley for proofreading the document. We would also like to thank M. Sc. Mikola Rasko, M. Sc. Rúben Mina and M. Sc. Sandra Simões for their contribution to the sampling process.

\section{Authors'contribution}


DP, SM, JA, AAS and JPS conceived the project and designed the methods; DP, SM, JFA and JMC collected the data; DP and JPS analysed the data; DP wrote the study. All authors made critical contributions to the draft and gave final approval for publication.

\section{Funding}

This research was funded by Programa Operacional Regional do Centro, grant number Centro-01-0145FEDER-000007 (ReNATURE), by the European Union's Horizon 2020 Research and Innovation programme, under Grant Agreement No. 773554 (EcoStack), and by Fundação para a Ciência e Tecnologia through the project PTDC/ASP-PLA/30003/2017 (OLIVESIM). JA was financed by FCT/MCTES, through national funds (PIDDAC), to the Centre for Functional Ecology - Science for People and the Planet (CFE), with the reference UIDB/04004/2020.

Compliance with ethical standards This article does not contain any studies with human participants or animals performed by any of the authors.

\section{References}

1. Abd El-Salam AME, Salem SA-W, Abdel-Rahman RS et al (2019) Effects of climatic changes on olive fly, Bactrocera oleae (Rossi) population dynamic with respect to the efficacy of its larval parasitoid in Egyptian olive trees. Bulletin of the National Research Centre 43. https://doi.org/10.1186/s42269019-0220-9

2. Batáry P, Dicks L, Kleijn D, Sutherland WJ (2015) The role of agri-environment schemes in conservation and environmental management. Conserv Biol 29:1006-1016. https://doi.org/10.1111/cobi.12536

3. Bates D, Mächler M, Bolker BM, Walker SC (2015) Fitting linear mixed-effects models using Ime4. J Stat Softw 67. https://doi.org/10.18637/jss.v067.i01

4. Benjamini Y, Hochberg Y (1995) Controlling the false discovery rate: a practical and powerful approach to multiple testing. Journal of the Royal Statistical Society Series B (Methodological) 57:289-300

5. Bianchi FJJA, Booij CJH, Tscharntke T (2006) Sustainable pest regulation in agricultural landscapes: A review on landscape composition, biodiversity and natural pest control. Proceedings of the Royal Society B: Biological Sciences 273:1715-1727

6. Block W (1990) Cold tolerance of insects and other arthropods. Philosophical Transactions - Royal Society of London, B 326:613-633. https://doi.org/10.1098/rstb.1990.0035

7. Chaplin-Kramer R, de Valpine P, Mills NJ, Kremen C (2013) Detecting pest control services across spatial and temporal scales. Agriculture, Ecosystems and Environment 181:206-212. https://doi.org/10.1016/j.agee.2013.10.007

8. Chaplin-Kramer R, O'Rourke ME, Blitzer EJ, Kremen C (2011) A meta-analysis of crop pest and natural enemy response to landscape complexity. Ecol Lett 14:922-932 
9. Clarke R (2018) Biogeographical and co-evolutionary origins of Why so many polyphagous fruit flies (Diptera: scarabaeine dung beetles : Mesozoic vicariance versus Tephritidae)? A further contribution to the ' generalism ' Cenozoic debate dispersal and dinosaur versus.245-257

10. Daane KM, Johnson MW (2010) Olive fruit fly: Managing an ancient pest in modern times. Ann Rev Entomol 55:151-169. https://doi.org/10.1146/annurev.ento.54.110807.090553

11. Dainese M, Martin EA, Aizen MA et al (2019) A global synthesis reveals biodiversity-mediated benefits for crop production. Sci Adv 5. https://doi.org/10.1126/sciadv.aax0121

12. Deutsch CA, Tewksbury JJ, Huey RB et al (2008) Impacts of climate warming on terrestrial ectotherms across latitude. Proc Natl Acad Sci USA 105:6668-6672. https://doi.org/10.1073/pnas.0709472105

13. Dirzo R, Young HS, Galetti M et al (2014) Defaunation in the Anthropocene. Science 345:401-406

14. European Comission (2020) A farm to fork strategy for a fair, healthy and enviromental-firiendly system. 21:1-9

15. Fletcher BS, Kapatos E (1981) Dispersal of the Olive Fly, Dacus Oleae, During the Summer Period on Corfu. Entomol Exp Appl 29:1-8. https://doi.org/10.1111/j.1570-7458.1981.tb03036.x

16. Foley JA, DeFries R, Asner GP et al (2005) Global consequences of land use. Science 309:570-574

17. Gould F, Brown ZS, Kuzma J (2018) Wicked evolution: Can we address the sociobiological dilemma of pesticide resistance? Science 360:728-732

18. Gutierrez AP, Ponti L, Cossu QA (2009) Effects of climate warming on Olive and olive fly (Bactrocera oleae (Gmelin)) in California and Italy. Clim Change 95:195-217. https://doi.org/10.1007/s10584008-9528-4

19. Karp DS, Chaplin-Kramer R, Meehan TD et al (2018) Crop pests and predators exhibit inconsistent responses to surrounding landscape composition. Proc Natl Acad Sci USA 115:E7863-E7870. https://doi.org/10.1073/pnas.1800042115

20. Kounatidis I, Papadopoulos NT, Mavragani-Tsipidou P et al (2008) Effect of elevation on spatiotemporal patterns of olive fly (Bactrocera oleae) populations in northern Greece. J Appl Entomol 132:722-733. https://doi.org/10.1111/j.1439-0418.2008.01349.x

21. Landis DA, Wratten SD, Gurr GM (2000) Habitat Management to Conserve Natural Enemies of Arthropod Pests in Agriculture. Ann Rev Entomol 45:175-201. https://doi.org/10.1146/annurev.ento.45.1.175

22. Manjón-Cabeza J, Paredes D, Campos M (2017) Influencia del paisaje en el control biológico por conservación de las plagas del olivo (Olea europaea). In: Simposium Expoliva. pp 10-12

23. Marchini D, Petacchi R, Marchi S (2017) Bactrocera oleae reproductive biology: New evidence on wintering wild populations in olive groves of Tuscany (Italy). Bull Insectol 70:121-128

24. Midega CAO, Jonsson M, Khan ZR, Ekbom B (2014) Effects of landscape complexity and habitat management on stemborer colonization, parasitism and damage to maize. Agriculture, Ecosystems and Environment 188:289-293. https://doi.org/10.1016/j.agee.2014.02.028 
25. Montiel-Bueno A, Jones $O$ (2001) Alternative methods for controlling the olive fly. IOBC-WPRS Bull 25:1-11

26. O'Rourke ME, Petersen MJ (2017) Extending the 'resource concentration hypothesis' to the landscape-scale by considering dispersal mortality and fitness costs. Agriculture, Ecosystems and Environment 249:1-3. https://doi.org/10.1016/j.agee.2017.07.022

27. Ortega M, Pascual S (2014) Spatio-temporal analysis of the relationship between landscape structure and the olive fruit fly Bactrocera oleae (Diptera: Tephritidae). Agric For Entomol 16:14-23. https://doi.org/10.1111/afe.12030

28. Paredes D, Rosenheim JA, Chaplin-Kramer R et al (2021) Landscape simplification increases vineyard pest outbreaks and insecticide use. Ecol Lett 24:73-83. https://doi.org/10.1111/ele.13622

29. Parry HR, Macfadyen S, Hopkinson JE et al (2015) Plant composition modulates arthropod pest and predator abundance: Evidence for culling exotics and planting natives. Basic Appl Ecol 16:531-543. https://doi.org/10.1016/j.baae.2015.05.005

30. Picchi MS, Bocci G, Petacchi R, Entling MH (2016) Effects of local and landscape factors on spiders and olive fruit flies. Agriculture, Ecosystems and Environment 222:138-147. https://doi.org/10.1016/j.agee.2016.01.045

31. Porcel M, Ruano F, Sanllorente $O$ et al (2009) Comunicación corta. Efecto del trampeo masivo tipo OLIPE sobre los artrópodos no objetivo del olivar. Spanish Journal of Agricultural Research 7:660664. https://doi.org/10.5424/sjar/2009073-459

32. Root RB (1973) Organization of a Plant-Arthropod Association in Simple and Diverse Habitats: The Fauna of Collards (Brassica Oleracea). Ecol Monogr 43:95-124. https://doi.org/10.2307/1942161

33. Rusch A, Chaplin-Kramer R, Gardiner MM et al (2016) Agricultural landscape simplification reduces natural pest control: A quantitative synthesis. Agriculture, Ecosystems and Environment 221:198204. https://doi.org/10.1016/j.agee.2016.01.039

34. Santoiemma G, Mori N, Tonina L, Marini L (2018) Semi-natural habitats boost Drosophila suzukii populations and crop damage in sweet cherry. Agriculture, Ecosystems and Environment 257:152158. https://doi.org/10.1016/j.agee.2018.02.013

35. Santoiemma G, Trivellato F, Caloi V et al (2019) Habitat preference of Drosophila suzukii across heterogeneous landscapes. J Pest Sci 92:485-494. https://doi.org/10.1007/s10340-018-1052-3

36. Scheffers BR, Edwards DP, Diesmos A et al (2014) Microhabitats reduce animal's exposure to climate extremes. Glob Change Biol 20:495-503. https://doi.org/10.1111/gcb.12439

37. Tamburini G, Santoiemma G, O'Rourke E M, et al (2020) Species traits elucidate crop pest response to landscape composition: A global analysis: Traits drive pest response to landscape. Proceedings of the Royal Society B: Biological Sciences 287: https://doi.org/10.1098/rspb.2020.2116rspb20202116

38. Thies C, Tscharntke T (1999) Landscape structure and biological control in agroecosystems. Science 285:893-895. https://doi.org/10.1126/science.285.5429.893 
39. Tscharntke T, Karp DS, Chaplin-Kramer R et al (2016) When natural habitat fails to enhance biological pest control - Five hypotheses. Biol Conserv 204:449-458

40. Wang XG, Johnson MW, Daane KM, Nadel H (2009) High summer temperatures affect the survival and reproduction of olive fruit fly (diptera: Tephritidae). Environ Entomol 38:1496-1504. https://doi.org/10.1603/022.038.0518

41. Wickham H (2016) Ggplot2: Elegant Graphics for Data Analysis. Springer-Verlag, New York 42. Wood SN (2011) Fast stable restricted maximum likelihood and marginal likelihood estimation of semiparametric generalized linear models. Journal of the Royal Statistical Society Series B: Statistical Methodology 73:3-36. https://doi.org/10.1111/j.1467-9868.2010.00749.x

\section{Figures}
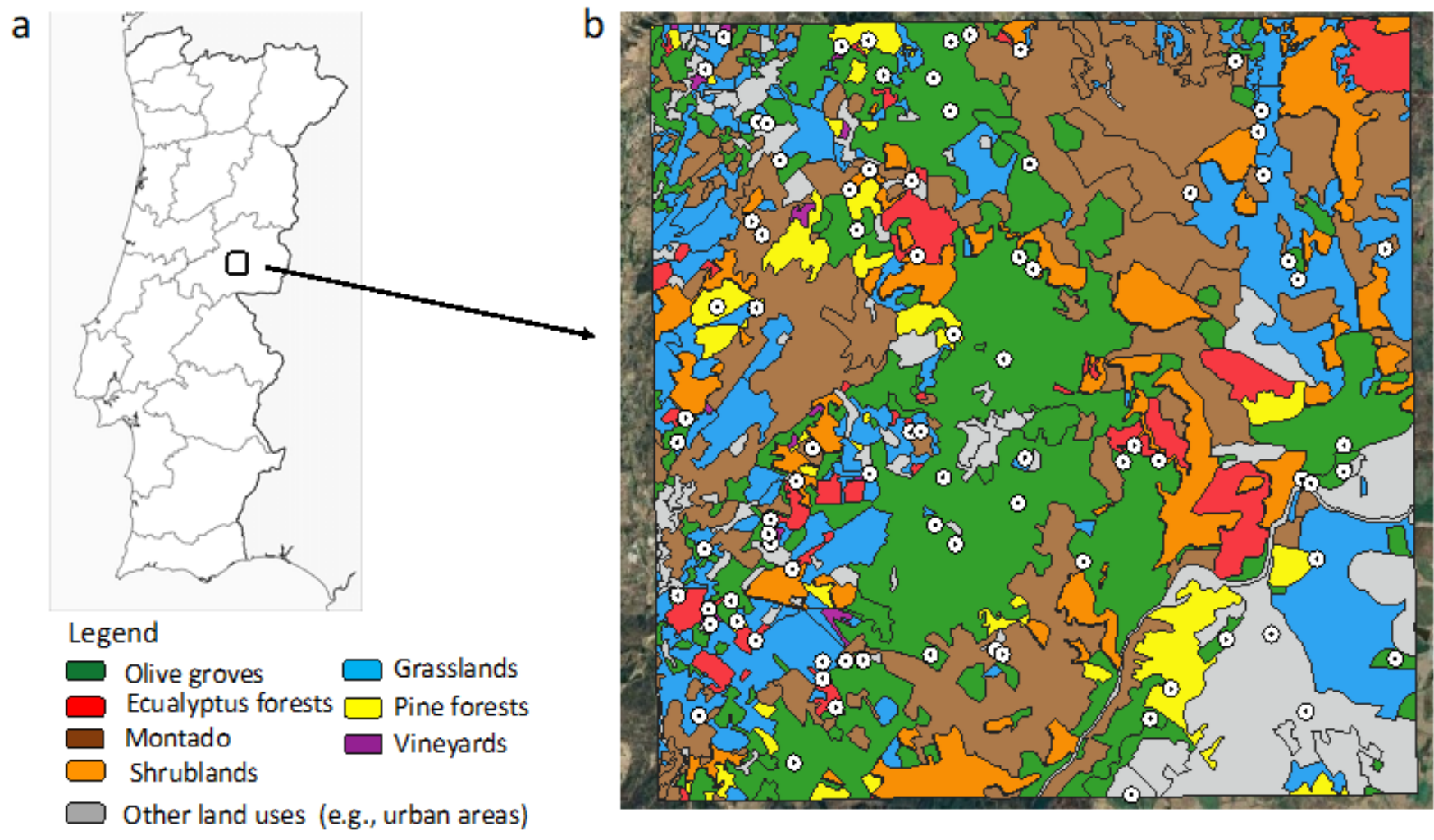

\section{Figure 1}

Location of the study area in Portugal (a) and distribution of sampling points across the different land uses of the study area (b). 


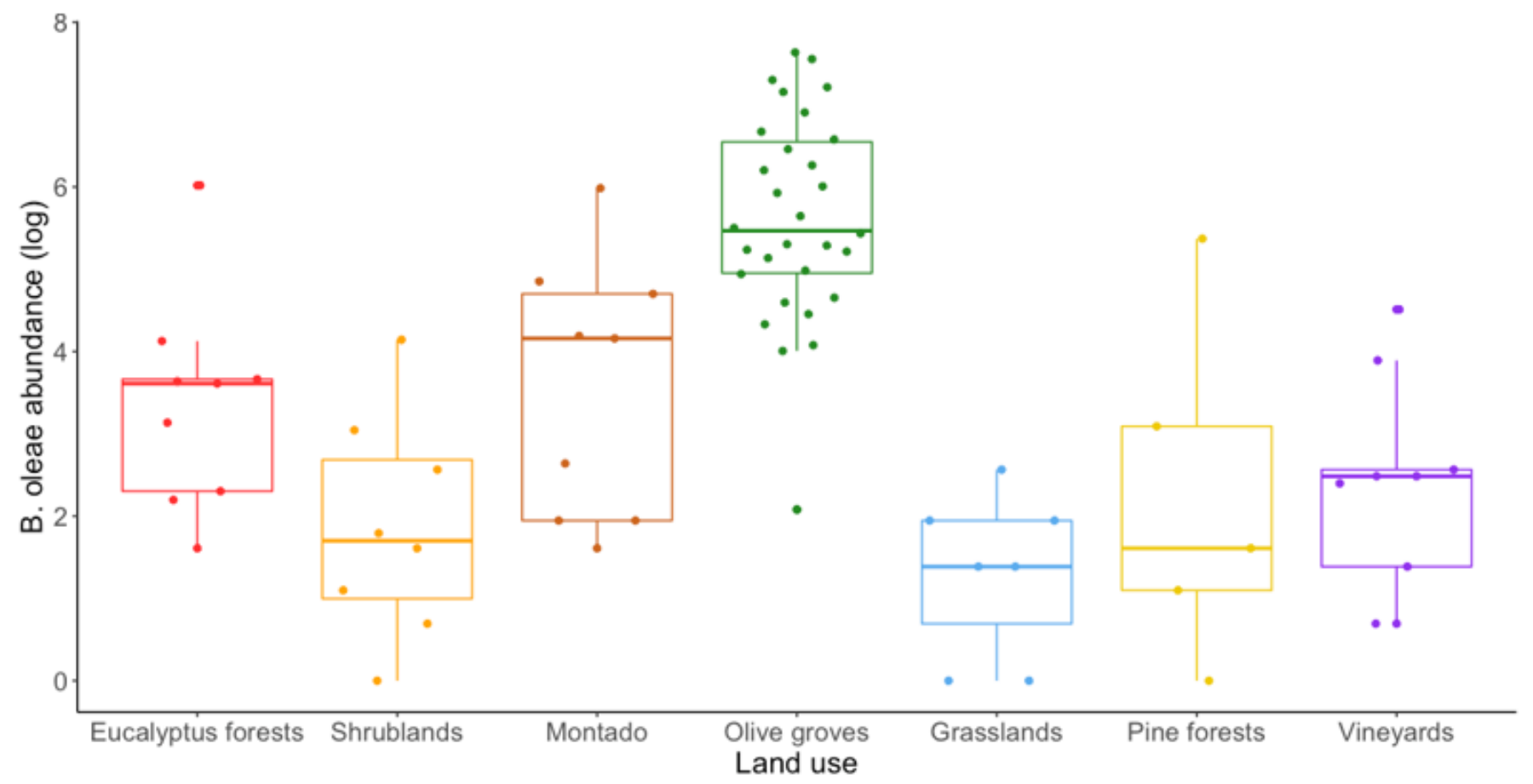

Figure 2

Boxplot of the logarithm of the abundance of B. oleae for the different land uses involved in the study. The top and bottom of the box are first quartile (Q1) and third quartile (Q3), and the centerline is median (Q2). Whiskers represent 1.5 times the IQR (Q3 - Q2) in relation to the upper and lower quartiles. Points represent the sampling points. 

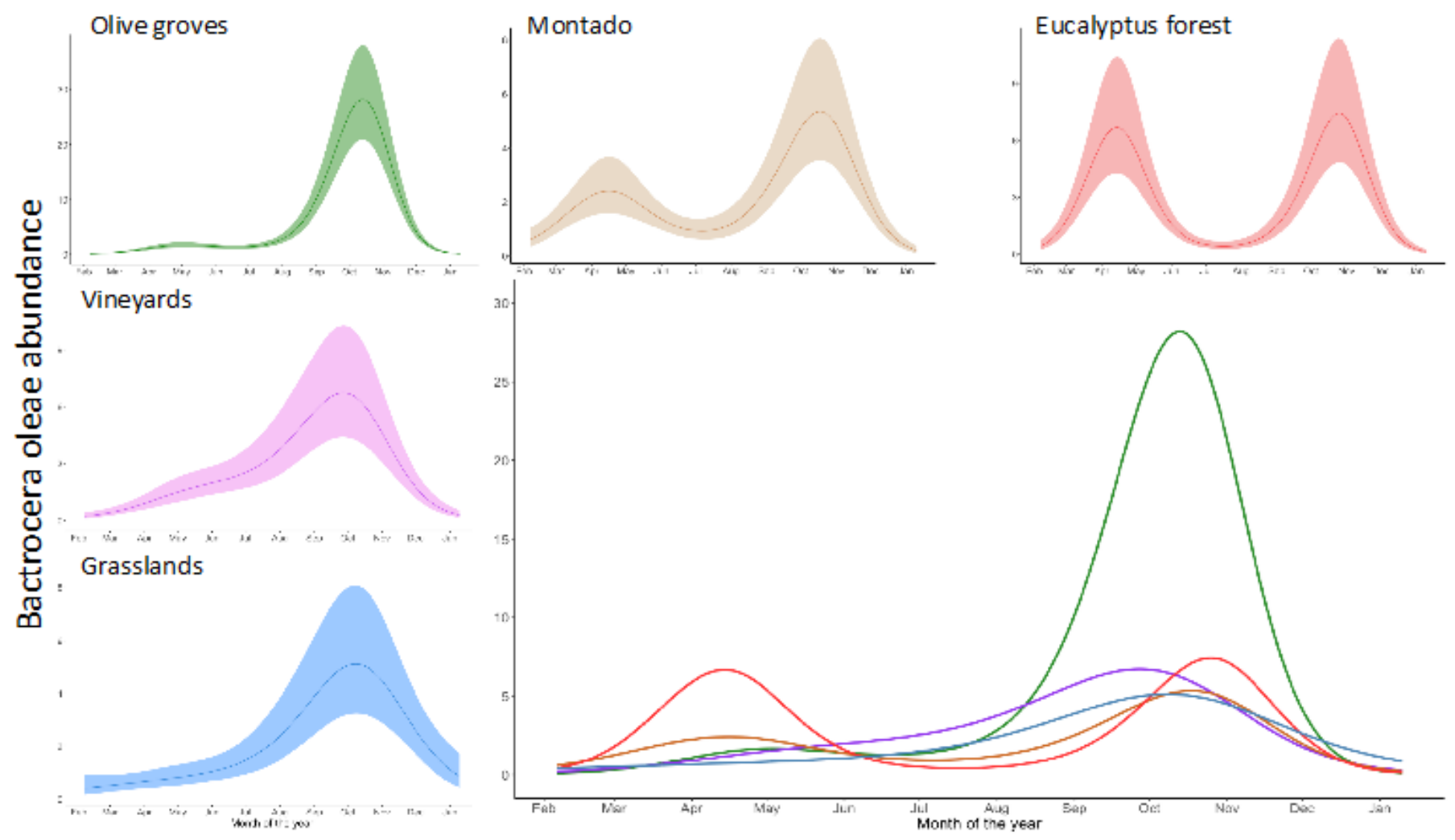

\section{Figure 3}

Bactrocera oleae temporal dynamics in the different land uses that compound the study along with the representation of all the dynamics together. Blue, pink, green, brown and red lines represent grasslands, vineyards, olive groves, "montado" and eucalyptus forests respectively. Shadowed areas represent the confident intervals at $95 \%$. 

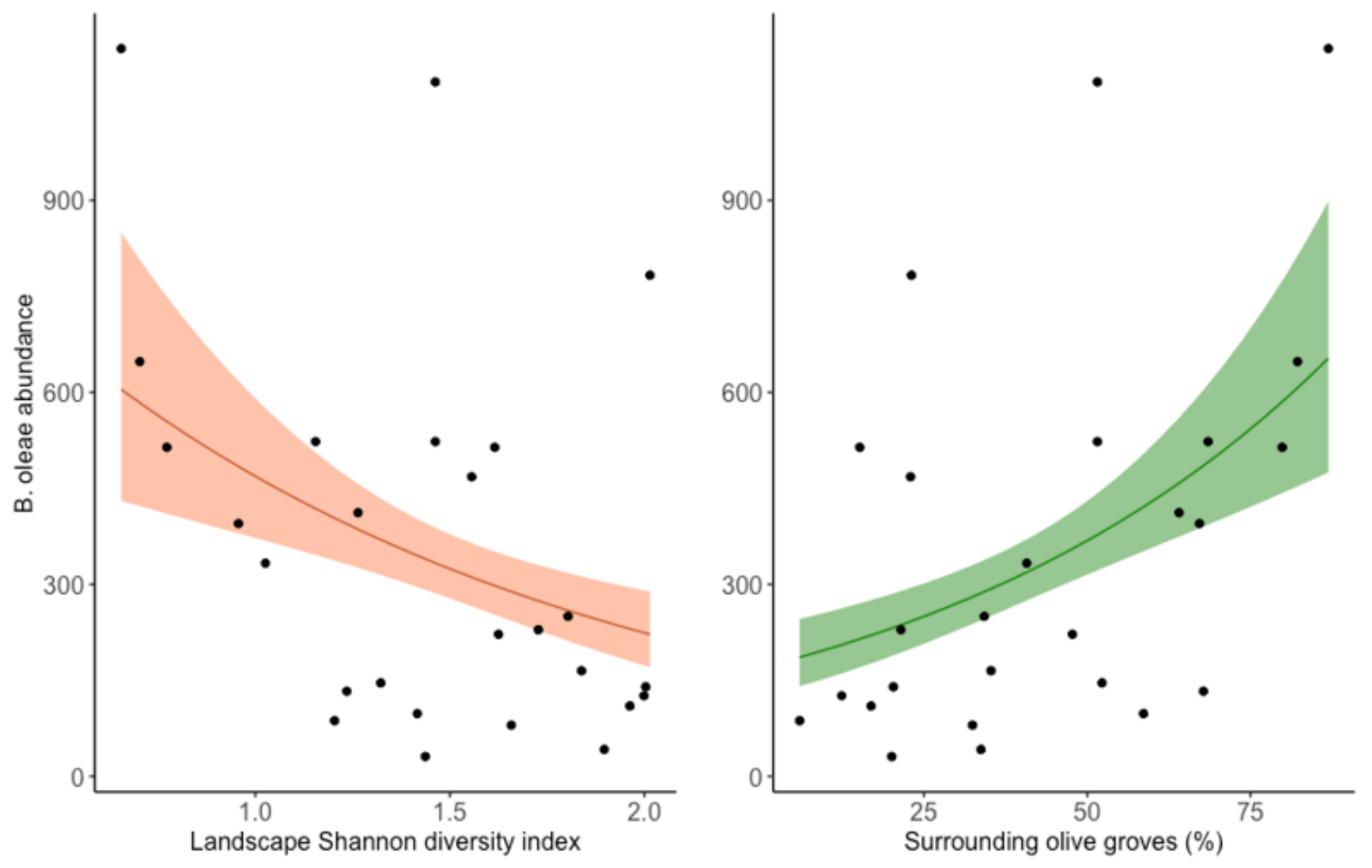

Figure 4

Estimated effects of gradients of landscape diversity (brown line) and landscape simplification (green line) on Bactrocera oleae abundance. Shadowed areas represent the confident intervals at $95 \%$. 